\title{
Working
}

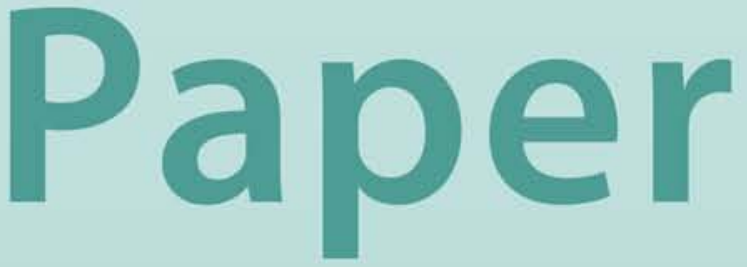




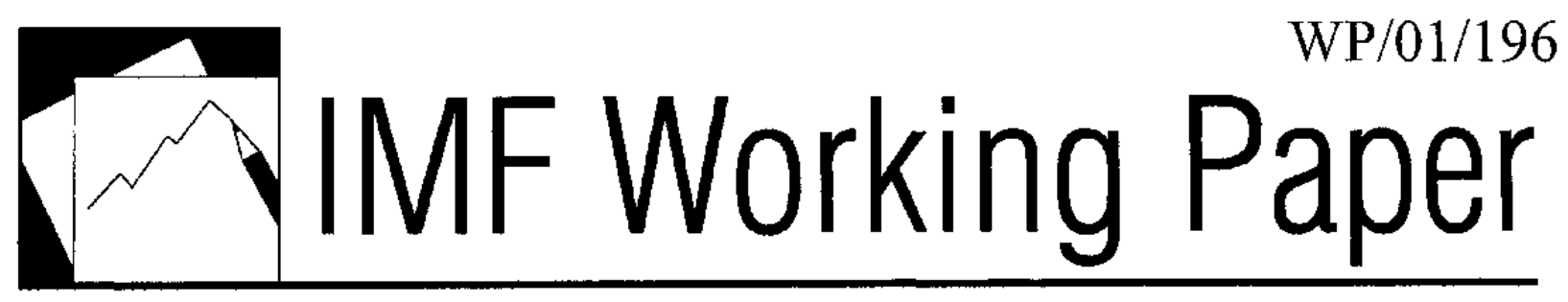

An Unbiased Appraisal of Purchasing
Power Parity

Paul Cashin and C. John McDermott 


\title{
IMF Working Paper
}

Research Department

\section{An Unbiased Appraisal of Purchasing Power Parity}

\author{
Prepared by Paul Cashin and C. John McDermott ${ }^{1}$ \\ Authorized for distribution by Miguel Savastano
}

December 2001

\begin{abstract}
The views expressed in this Working Paper are those of the author(s) and do not necessarily represent those of the IMF or IMF policy. Working Papers describe research in progress by the author(s) and are published to elicit comments and to further debate.
\end{abstract}

Univariate studies of the hypothesis of unit roots in real exchange rates have yielded consensus point estimates of the half-life of deviations from purchasing power parity of between three to five years. However, least squares-based estimates of half-lives are biased downward. Accordingly, we follow Andrews (1993) and use median-unbiased estimators of the half-life of deviations from parity as a preferred measure of the persistence of real exchange rate shocks. We study this issue using real effective exchange rate (REER) data for 22 industrial countries in the post-Bretton Woods period. Three methods of bias correction are implemented, which yield cross-country averages of half-lives of deviations from parity ranging between 4 to 15 years, with the REER of several countries displaying permanent deviations from parity.

JEL Classification Numbers: C22; F31

Keywords: Median-unbiased estimation; purchasing power parity; shock persistence Authors' E-Mail Addresses: Pcashin@imf.org; John.Mcdermott@nbnz.co.nz

\footnotetext{
${ }^{1}$ IMF Research Department and National Bank of New Zealand, respectively. The authors thank Peter Clark, Geoffrey Kingston, Sam Ouliaris, Kenneth Rogoff, Miguel Savastano, Peter Wickham and seminar participants at the International Monetary Fund, the Sixth Australian Macroeconomics Workshop (University of Adelaide) and New Zealand Exchange Rate Workshop (Victoria University of Wellington) for their comments and suggestions. The views expressed are those of the authors, and do not necessarily represent those of the International Monetary Fund or the National Bank of New Zealand.
} 
I. Introduction

II. Biased and Unbiased Measures of Half-Lives of Shocks to Parity ................................... $\underline{6}$

A. Problems with Standard (Least Squares) Measures of the Half-Life of Shocks to Parity.

B. Bias-Correcting Estimates of the Autoregressive Parameter and the Model

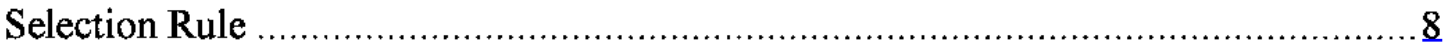

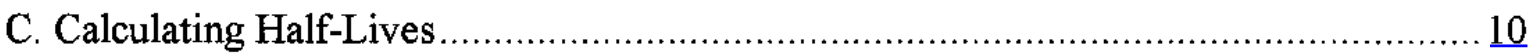

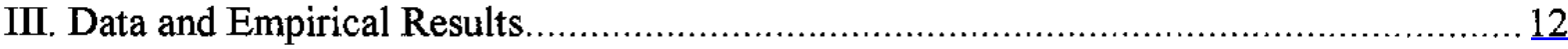

A. Biased Least Squares Estimates of Half-Lives of Parity Reversion ........................ 18

B. Median-Unbiased Estimates of Half-Lives of Parity Reversion .................................23

C. What Might Be Causing Highly-Persistent Deviations from PPP?...........................28

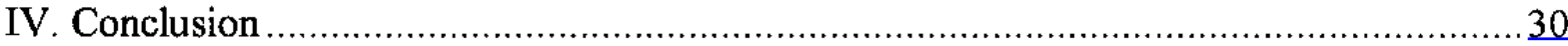

Text Tables

1. Least Squares Half-Lives of Parity Deviations in Dickey-Fuller Regressions.................. 19

2. Least Squares Half-Lives of Parity Deviations in Augmented

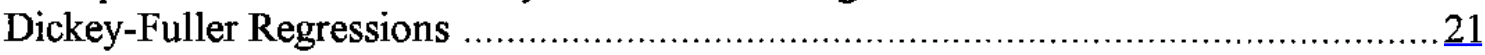

3. Least Squares Half-Lives of Parity Deviations in Phillips-Perron Regressions .................22

4. Median Unbiased Half-Lives of Parity Deviations in Dickey-Fuller Regressions .............24

5. Median Unbiased Half-Lives of Parity Deviations in Augmented Dickey-Fuller

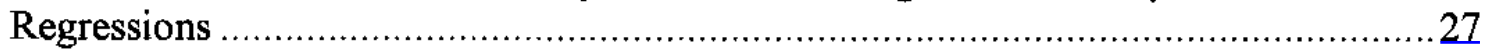

6. Median Unbiased Half-Lives of Parity Deviations in Phillips-Perron Regressions ..........22

Figure

1. Real Effective Exchange Rate, (base $1995=100$ ), Industrial Countries

References 


\section{INTRODUCTION}

Do real exchange rates really display parity-reverting behavior? In summarizing the results from studies using long-horizon data, Froot and Rogoff (1995) and Rogoff (1996) report the current consensus in the literature that the half-life of a shock (the time it takes for the shock to dissipate by 50 percent) to the real exchange rate is about three to five years, implying a slow parity reversion rate of between 13 to 20 percent per year. ${ }^{2}$ Such a slow speed of reversion to purchasing power parity is difficult to reconcile with nominal rigidities, and, as pointed out by Rogoff (1996), is also difficult to reconcile with the observed large short-term volatility of real exchange rates.

In earlier work, Meese and Rogoff (1983) demonstrated that a variety of linear structural exchange rate models failed to forecast more accurately than a naïve random walk model for both real and nominal exchange rates. If the real exchange rate follows a random walk, then innovations to the real exchange rate persist and the time series can fluctuate without bound. This result is contrary to the theory of purchasing power parity (PPP), which at its most basic level states that there is an equilibrium level to which exchange rates converge, such that foreign currencies should possess the same purchasing power. ${ }^{3}$

Notwithstanding the abovementioned consensus in the literature on the speed of parity reversion, the conclusion of Meese and Rogoff (1983) has been reached in many subsequent studies of the time series properties of the real exchange rate. Typically, this conclusion has been derived using formal statistical tests that failed to reject the null hypothesis of a unit root in the real exchange rate against the alternative of a stationary autoregressive (AR) model. If the unit root model can characterize real exchange rate behavior, then PPP does not hold because there is no propensity to revert back to any equilibrium level.

${ }^{2}$ Abuaf and Jorion (1990) use data on bilateral real exchange rates between the United States and several industrial countries during the $20^{\text {th }}$ Century, and find average half-lives of a little over 3 years. Frankel (1986) and Lothian and Taylor (1996) use two centuries of annual data on the pound-dollar real exchange rate in calculating half-lives of about 5 years. Wu (1996) and Papell (1997) use panel data methods on quarterly post-Bretton Woods data to derive half-lives of between two to three years.

${ }^{3}$ The version of PPP with the longest pedigree is that of relative PPP, which states that the exchange rate will be proportional to the ratio of money price levels (including traded and nontraded goods) between countries, that is to the relative purchasing power of national currencies (see Wickham (1993)). For recent surveys on PPP and exchange rate economics, see Isard (1995) and Froot and Rogoff (1995). 
The empirical literature on testing the existence of PPP has developed in tandem with developments in the unit root econometrics literature, and has taken several paths. First, a standard rationale for the inability of researchers to clearly reject the unit root null, especially in the post-Bretton Woods period, is that unit root tests have low power because of the relatively short sample periods under study. In response, long-run data of a century or more, which span several exchange rate regimes, have been analyzed to improve the power of unit root tests (see Frankel (1986), Lothian and Taylor (1996), among others). Second, panel data methods have been used in an attempt to increase the power of unit root tests (see Frankel and Rose (1996) and Wu (1996), among others). ${ }^{4}$ Third, as PPP implies cointegration between the nominal exchange rate, domestic price level and foreign price level, multivariate tests of the null hypothesis of no cointegration between these three variables have been carried out (see Corbae and Ouliaris (1988) and Edison et. al (1997), among others). Typically, both the long-run data and panel approaches have produced results which more frequently reject the unit root null for real exchange rates, while (particularly for post-Bretton Woods data) the results from cointegrating regressions have varied widely in their ability to reject the null of no cointegration (Froot and Rogoff (1995)).

However, one aspect of unit root econometrics that has been largely neglected in the PPP literature is the problem of "near unit root bias", which biases empirical results in favor of finding PPP. An important pitfall in using the autoregressive or unit root model to analyze the persistence of shocks to the real exchange rate is that standard estimators, such as least squares, are significantly downwardly biased in models that contain constants or time trends, especially when the true autoregressive parameter is close to but less than one. This bias causes the least squares estimator to be a misleading indicator of the true value of both the autoregressive parameter and the rate of reversion to parity. ${ }^{5}$

In this paper we will generate a transformation from some initial estimator to a median-unbiased estimator, in order to correct for the near unit root bias. Median-unbiased estimators for autoregressive models have been proposed by Andrews (1993), Andrews and Chen (1994), McDermott (1996), and earlier by Rudebusch (1992), and Stock (1991). The median unbiased estimators employed in this paper are based on initial estimators that

\footnotetext{
${ }^{4}$ The results of the recent burst of activity in the conduct of univariate tests of PPP have been characterized by Taylor (2000) as either in the "whittling down half-lives" camp (such as Frankel and Rose (1996) and Wu (1996)) or the "whittling up half-lives" camp (such as Papell (1997), O'Connell (1998) and Engel (2000)). The latest wave in this research is supportive of the latter camp, which cast doubt on the stationarity of international relative prices.

${ }^{5}$ While this bias is certainly present in standard (least squares) estimation of the unit root model, panel-data methods (such as those applied by Wu (1996), Papell (1997) and Taylor and Sarno (1998)), which pool cross-country information, will also be subject to the near unit root bias that lowers the estimated rate of reversion to parity (see Cermeno (1999)).
} 
include Dickey-Fuller unit root regressions, and Augmented Dickey-Fuller unit root regressions. Importantly, we also use the initial estimators proposed by Phillips (1987) and Phillips and Perron (1988), which, given they are robust to weakly dependent and heterogeneously distributed time series, may be better suited than alternative median unbiased estimators for modeling real exchange rates.

Conventional analyses of whether real exchange rates are better modeled as stationary or random walk processes typically focus on whether real exchange rate shocks are mean reverting (finite persistence) or not (permanent). Such tests of the null hypothesis of a unit root in real exchange rates are rather uninformative as to the speed of parity reversion, because a rejection of the unit root null could still be consistent with a stationary model of real exchange rates that has highly-persistent shocks. In contrast, this paper concentrates on measuring the duration of shocks to the real exchange rate and associated confidence intervals, and undertakes no hypothesis tests as to the suitability of the assumption of a unit root as the process governing the evolution of real exchange rates. Instead of unit root tests, in this paper we characterize the extent of parity reversion in terms of point and interval estimates of the half-life of deviations from purchasing power parity, where the half-life is typically defined as the duration of time required for half the magnitude of a unit shock to the level of a series to dissipate. Point and interval estimators are useful statistics for providing information to draw conclusions about the relevance of PPP, as unlike hypothesis tests they are informative when a hypothesis is not rejected, and will be used in this paper.

The contributions of this paper are fourfold. First, the median-unbiased estimator of Andrews (1993) and Andrews and Chen (1994) is used to obtain point and interval estimates of the autoregressive parameter in the real exchange rate data. These medianunbiased estimators are generated from a transformation of an initial estimator, and correct for the downward bias in standard (least squares) estimation of the autoregressive parameter in unit root models. Second, we follow McDermott (1996) and use median-unbiased estimators that allow for initial estimators that display a wider class of error processes (particularly a moving average error structure) than previously considered in the literature. Third, these unbiased estimates of the autoregressive parameter and associated impulse response functions are used to calculate an unbiased scalar measure of the average duration (in terms of half-lives) and range of typical real exchange rate shocks. Fourth, using an unbiased model-selection rule we can overcome the low power problems inherent in unit root tests of PPP, and be more definitive about our willingness to accept the null (of no PPP) in the post-Bretton Woods period. Our results indicate that unbiased estimates of the half-lives of deviations of real exchange rates from purchasing power parity are longer than the previous consensus allows for. In particular, we find that for at least seven countries these deviations from purchasing power parity are best viewed as being permanent.

The remainder of the paper is as follows. Section II sets out the median-unbiased procedure for estimation of autoregressive (or unit root) models, which are used to examine the persistence of real exchange rate shocks. It also describes the three types of initial estimators used to provide point estimates of the autoregressive parameter in unit root models. Section III describes the data used in the study, and presents the main empirical findings regarding the point estimates of the persistence of shocks to the real exchange rate, 
and the estimated confidence intervals used to gauge the level of uncertainty of these estimates of the true half-life of real exchange rate shocks. Section IV provides some concluding comments.

\section{BIASEd AND UNBIASEd Measures of Half-Lives of Shocks to PaRITy}

The existence of long-run PPP is inconsistent with unit roots in the real exchange rate process. This notion has stimulated the growth of a large literature, using various tests, to resolve whether PPP holds in the post-Bretton Woods period. However, analyses of the trend-stationary or difference-stationary dichotomy of standard unit root tests focus only on whether such shocks are mean-reverting (finite persistence) or not (permanent). For economists, long-run PPP means more than the absence of a unit root-it also means whether there is a sufficient degree of mean reversion in exchange rates (over the horizon of interest) to validate the theoretical predictions of models based on the PPP assumption. For example, using the Dornbusch (1976) overshooting model, which has plausible assumptions about nominal wage and price rigidities, we would expect substantial convergence of real exchange rates to PPP over one to two years. Rather than use unit root tests to evaluate PPP it is preferable to use a scalar measure of the speed of reversion of real exchange rate shocks, and recent papers examining the post-Bretton Woods period have used estimates of the half-life of deviations from PPP to do so (Andrews (1993), Andrews and Chen (1994), and Cheung and Lai (2000b)). ${ }^{6}$

To estimate the speed of convergence to purchasing power parity (PPP) most researchers use the first-order autoregressive (AR(1)) model of the univariate time series $\left\{q_{t}: t=0, \ldots, T\right\}$, assuming independent identically distributed normal errors. The model considered is

$$
q_{t}=\mu+\alpha q_{t-1}+\varepsilon_{t} \quad \text { for } t=1, \ldots, T
$$

where $q_{t}: t=0, \ldots, T$ is the real exchange rate, $\mu$ the intercept, $\alpha$ the autoregressive parameter (where $\alpha \in(-1,1]$ ), and $\varepsilon_{t}$ are the innovations of the model. A time trend is typically not included in equation ( 1 ), as a trend would not be consistent with long-run PPP (which imposes the restriction that real exchange rates have a constant unconditional mean). ${ }^{7}$

\footnotetext{
${ }^{6}$ Point and interval estimates of the half-life of shocks to economic time series have also been used by Cashin, Liang and McDermott (2000) in modeling the persistence of shocks to world commodity prices. Earlier, Stock (1991) considered point and asymptotic confidence intervals for the largest autoregressive root in a time series.

${ }^{7}$ Time trends are sometimes included in tests of PPP in an attempt to control for the BalassaSamuelson effect, where the failure of PPP to hold can be due to differential rates of productivity growth in the tradable and nontradable sectors.
} 
This model is the same as that used for testing whether there is a unit root in a time series-consequently, this model is often referred to as the Dickey-Fuller regression. The half-life, which is the time it takes for a deviation from PPP to dissipate by 50 percent, is calculated from the autoregressive parameter, $\alpha$ (see Section II.C below for details).

\section{A. Problems with Standard (Least Squares) Measures of the Half-Life of Shocks to Parity}

There are three problems with using these half-lives as evidence of the persistence of PPP deviations: biased autoregressive parameter coefficients; no confidence interval around the half-life measures; and serially correlated and heteroskedastic errors. We discuss each of these problems in turn.

First, it has been known since the work of Orcutt (1948) that least squares estimates of lagged dependent variable coefficients (such as the autoregressive parameter in the Dickey-Fuller regression) will be biased towards zero in small samples. The literature on the bias of least squares estimation of autoregressive models is an old one. Marriott and Pope (1954) established the mean-bias of the least squares estimator for the stationary AR(1) model, as did Shaman and Stine (1989) for stationary $\operatorname{AR}(p)$ models. While least squares will be the best linear unbiased estimator under the Gauss-Markov theorem, in the autoregressive case the assumptions of this theorem are violated, as lagged values of the dependent variable cannot be fixed in repeated sampling, nor can they be treated as distributed independently of the error term for all lags. Marriott and Pope (1954) showed that, ignoring second-order terms, the expected value of the least squares estimate of the true $\alpha$ in the AR(1) model of equation (1) can be approximated by: $\mathrm{E}(\hat{\alpha})=\alpha-(1+3 \alpha) / N$, where $N=T-1$. Using simulation calculations, Orcutt and Winokur (1969) find that, for $T=40$ and true $\alpha=1$, the least squares mean bias is $\mathrm{E}(\hat{\alpha})-\alpha=0.129$. Similarly, the simulation calculations of Andrews (1993) reveal that the least squares median bias of equation (1), again for $T=40$ and true $\alpha=1$, is slightly smaller at 0.107 . In general, the larger is the true value of $\alpha$, the larger is the least squares bias, and so the bias is largest in the unit root case. The bias shrinks as the sample size grows, as the estimate converges to the true population value.

The downward bias in least squares estimates of the autoregressive parameter arises because there is an asymmetry in the distribution of estimators of the autoregressive parameter in AR models. The distribution is skewed to the left, resulting in the median exceeding the mean. As a result, the median is a better measure of central tendency than the mean in least squares estimates of Dickey-Fuller models. The exact median-unbiased estimation procedure proposed by Andrews (1993) can be used to correct this bias. The bias correction delivers an impartiality property to the decision making process, because there is an equal chance of under- or over-estimating the autoregressive parameter in the unit root regression. Moreover, an unbiased estimate of $\alpha$ will allow us to calculate an unbiased scalar estimate of persistence- the half life of a unit shock. 
Second, reporting only point estimates of the half-lives provides an incomplete picture of the speed of convergence towards PPP. To gain a more complete view one should use interval estimates. Fortunately, median-unbiased estimation allows for the calculation of median-unbiased confidence intervals. Moreover, interval estimation addresses the low power problem, usually associated with unit root tests (DeJong et al. (1992)), by informing us whether we are failing to reject the null because it is true or because there is too much uncertainty as to the true value of the autoregressive parameter.

Third, the presence of serial correlation (typical in economic time series) means that the Dickey-Fuller regression will often not be appropriate. In such cases, we can follow Andrews and Chen (1994) and use an AR( $p)$ model, which adds lagged first differences to account for serial correlation. The $\operatorname{AR}(p)$ model (also known as an Augmented Dickey-Fuller (ADF) regression) takes the form

$$
q_{t}=\mu+\alpha q_{t-1}+\sum_{i=1}^{p-1} \psi_{i} \Delta q_{t-i}+\varepsilon_{t} \text { for } t=1, \ldots, T
$$

where the observed real exchange rate series is $q_{t}: t=-p, \ldots, T$. Andrews and Chen (1994) show how to perform approximately median-unbiased estimation of autoregressive parameters in ADF regressions.

While Andrews (1993) assumes iid errors and Andrews and Chen (1994) assume $\operatorname{AR}(p)$ errors, neither approach allows for the possibility of a MA error structure (unless $p \rightarrow \infty$ as $\mathrm{T} \rightarrow \infty$ ). If moving average and heteroskedastic errors are present, then even the Andrews-Chen method may not account for the biases arising from these attributes of the data. One method which can deal with more general error processes than those used in previous work is the semi-nonparametric technique of the Phillips-Perron (1988) unit root regression, which estimates the model of equation (1), and accounts for serial correlation and heteroskedasticity using nonparametric methods. We implement this method in this paper, using the approach of McDermott (1996), who applied a median-bias correction to the Phillips-Perron (PP) regression.

\section{B. Bias-Correcting Estimates of the Autoregressive Parameter and the Model Selection Rule}

Andrews (1993) presents a method for median-bias correcting the least squares estimator. A median-unbiased estimate is the value of $\alpha$ for which the median of the distribution of the least squares estimator equals the actual least squares estimate of $\alpha$. This implies removing the median-bias from the actual least squares estimate of $\alpha$. To calculate the median-unbiased estimator of $\alpha$, suppose $\hat{\alpha}$ is an estimator of the true $\alpha$ whose median function $(m(\alpha))$ is uniquely defined $\forall \alpha \in(-1,1]$. Then $\hat{\alpha}_{u}$ (the median unbiased estimator of $\alpha$ ) is defined as: 


$$
\hat{\alpha}_{u}=\left\{\begin{array}{c}
1 \text { if } \hat{\alpha}>m(1), \\
m^{-1}(\hat{\alpha}) \text { if } m(-1)<\hat{\alpha} \leq m(1), \\
-1 \text { if } \hat{\alpha} \leq m(-1)
\end{array}\right.
$$

where $m(-1)=\lim _{\alpha \rightarrow-1} m(\alpha)$, and $m^{-1}:(m(-1), m(1)] \rightarrow(-1,1]$ is the inverse function of $m($.$) that$ satisfies $m^{-1}(m(\alpha))=\alpha$ for $\alpha \in(-1,1]$. That is, if we have a function that for each true value of $\alpha$ yields the median value ( 0.50 quantile) of $\hat{\alpha}$, then we can simply use the inverse function to obtain a median unbiased estimate of $\alpha$. To calculate the median-unbiased estimator, we find the value of $\alpha$ that results in the least squares estimator having a median value of $\hat{\alpha}$. For example, if the least squares estimate of $\alpha$ equals 0.8 then we do not use that estimate, but instead use that value of $\alpha$ which results in the least squares estimator having a median of 0.8 . The extent of the median bias rises with the persistence of the innovations, which is particularly important for near unit root series such as the real exchange rate, which in the literature have previously (using point estimates of $\alpha$ ) been found to be stationary, yet with shocks that are rather persistent.

The median-unbiased estimator can also be used to derive an unbiased modelselection rule, where for any correct model the probability of selecting the correct model is at least as large as the probability of selecting each incorrect model (Andrews (1993), Andrews and Chen (1994)). ${ }^{9}$ Suppose the problem is to select one of two models defined by $\alpha \in I_{a}$ and $\alpha \in I_{b}$, where $I_{a}$ and $I_{b}$ are intervals partitioning the parameter space $(-1,1]$ for $\alpha$, with $I_{a}=(-1,1)$ and $I_{b}=\{1\}$. Then the unbiased model selection rule would indicate that model $I_{m}$ should be chosen if $\hat{\alpha}_{u} \in I_{m}$, for $m=a, b$. This is also a valid level 0.50 (unbiased) test of the $H_{0}: \alpha \in I_{a}$ versus $H_{l}: \alpha \in I_{b}$.

${ }^{8}$ Other sources of bias in estimation of unit root regressions have been examined in the large literature on PPP, which will not be examined in this paper. These include: large size biases in univariate tests for long-run PPP, due to a significant unit root component in the relative price of nontraded goods (Engel (2000)), and in multivariate tests for long-run PPP due to a failure to control for cross-sectional correlation (O'Connell (1998)); and sample-selection bias of the countries analyzed, which biases the results toward understating the general relevance of parity reversion (Cheung and Lai (2000a)).

${ }^{9}$ The unbiased model selection procedure based on the median-unbiased estimate of the AR(I) model is an exact test, as are its associated confidence intervals. However, the unbiased model selection procedure based on the median-unbiased estimate of the $\operatorname{AR}(p)$ model is an approximate test, as are its associated confidence intervals. This is because the distribution of $\hat{\alpha}_{u}$ calculated from the $\operatorname{AR}(p)$ model depends on the true values of the $\psi_{\mathrm{i}}$ terms in equation (2), which are unknown. Andrews and Chen (1994) demonstrate that the approximately median-unbiased point and interval estimates of $\alpha$ in the $\operatorname{AR}(p)$ model are very close to being median-unbiased. A similar unbiased model selection procedure can be invoked for the PP regression, and this is also an approximate test because of the need to estimate the serial correlation correction. 
Importantly, the median-unbiased estimator $\hat{\alpha}_{u}$ is the lower and upper bounds of the two one-sided 0.5 confidence intervals for the true $\alpha$ when $m($.$) is strictly increasing$ (Andrews (1993), p.152). These confidence intervals have the property that their probabilities of encompassing the true $\alpha$ are one-half. That is, there is a 50 percent probability that the confidence interval from minus one to $\hat{\alpha}_{u}$ contains the true $\alpha$, and a 50 percent probability that the confidence interval from $\hat{\alpha}_{u}$ to one contains the true $\alpha$. For example, if $\hat{\alpha}_{u}=0.90$, then the probability that the true $\alpha$ is less than 0.90 is one half, and the probability that the true $\alpha$ exceeds 0.90 is also one half.

Based on the median-unbiased estimate of $\alpha$, other tests with different size and power properties can also be constructed. Using the 0.05 and 0.95 quantile functions of $\hat{\alpha}$, we can construct two-sided 90 percent confidence intervals or one-sided 95 percent confidence intervals for the true $\alpha$. These confidence intervals can be used either to provide a measure of the accuracy of $\hat{\alpha}$, or to construct the conventional exact one- or two-sided tests of the null hypothesis that $\alpha=\alpha_{0}$. In this paper we use such confidence intervals only to provide a measure of the accuracy of $\hat{\alpha}$.

In a Monte Carlo study of the $\operatorname{AR}(p)$ model, Andrews and Chen (1994, p.194) demonstrate that the unbiased model-selection rule has a probability of correctly selecting the unit-root model (when the true $\alpha=1$ ) of about 0.5 . This is much lower than the corresponding probability for a (two-sided) level 0.10 test or (one-sided) level 0.05 test of a unit-root null hypothesis, as the unbiasedness condition does not (unlike the level 0.10 or 0.05 tests) give a bias in favor of the unit root model. The greater size of Andrews' unbiased model selection rule, in comparison with conventional tests, increases the probability of rejecting the unit root null. This suggests that if the true $\alpha<1$, then the power of Andrews' rule will be larger than for conventional tests, especially for the near unit root case.

\section{Calculating Half-Lives}

Our interest in this paper concerns the persistence of shocks to economic time series. In this connection, the impulse response function of a time series $\left\{q_{t}: t=1,2, \ldots\right\}$ measures the effect of a unit shock occurring at time $t$ (that is, $\varepsilon_{t} \rightarrow \varepsilon_{t}+1$ in equations (1) and (2)) on the values of $q_{t}$ at the future time periods $t+1, t+2, \ldots$ This function quantifies the persistence of shocks to individual time series. For the AR(1) model the impulse response function is given by

$$
\operatorname{IR}(h)=\alpha^{h} \text { for } h=0,1,2, \ldots
$$

For an $\operatorname{AR}(p)$ model the impulse response function is given by

$$
\operatorname{IR}(h)=f_{11}{ }^{(h)} \text { for } h=0,1,2, \ldots,
$$

where $f_{11}{ }^{(h)}$ denotes the $(1,1)$ element of $\mathbf{F}^{h}$ and where $\mathbf{F}$ is the $(p \times p)$ matrix 


$$
F \equiv\left[\begin{array}{cccccc}
\alpha_{1} & \alpha_{2} & \alpha_{3} & \cdots & \alpha_{p-1} & \alpha_{p} \\
1 & 0 & 0 & \cdots & 0 & 0 \\
0 & 1 & 0 & \cdots & 0 & 0 \\
\vdots & \vdots & \vdots & \cdots & \vdots & \vdots \\
0 & 0 & 0 & \cdots & 1 & 0
\end{array}\right]
$$

However, rather than consider the whole impulse response function to gauge the degree of persistence we use a scalar measure of persistence that summarizes the impulse response function: the half-life of a unit shock (HLS). For the AR(1) model (with $\alpha \geq 0$ ), the HLS gives the length of time until the impulse response of a unit shock is half its original magnitude, and is defined as $\mathrm{HLS}=\mathrm{ABS}(\log (1 / 2) / \log (\alpha))$. Since median-unbiased estimates of $\alpha$ have the desirable property that any scalar measures of persistence calculated from them (such as half-lives) will also be median unbiased, we can calculate the median-unbiased estimate of HLS by inserting the median-unbiased estimate of $\alpha$ in the formula for HLS. Similarly, the 90 percent confidence interval of the exactly median-unbiased Dickey-Fuller estimate of the HLS is calculated using the 0.05 and 0.95 quantiles of $\hat{\alpha}$ in the formula for HLS.

Median-unbiased point estimates and confidence intervals for the HLS are calculated in a similar fashion for the Phillips-Perron estimator of equation (1). The median-unbiased estimate of the HLS is calculated using the median-unbiased Phillips-Perron estimate of $\alpha$ (using the approach of McDermott (1996)) in the formula for the HLS. Similarly, the 90 percent confidence interval of the median-unbiased Phillips-Perron estimate of the HLS is calculated using the 0.05 and 0.95 quantiles of $\hat{\alpha}$ in the formula for HLS. ${ }^{10}$

The half-life derived from the values of $\alpha$ assumes that shocks decay monotonically. While appropriate for the AR(1) model, this assumption is inappropriate for an $\operatorname{AR}(p)$ model (with $p>1$ ), since in general shocks to an $\operatorname{AR}(p)$ will not decay at a constant rate. Instead, using the approach of Andrews and Chen (1994), the approximately median-unbiased point estimate of the half-life for $\operatorname{AR}(p)$ models (such as the ADF regression) can be calculated from the impulse response functions of equation (5), with the half-life defined as the time it takes for a unit impulse to dissipate by one half from the occurrence of the initial shock. Similarly, the 90 percent confidence interval of the approximately median-unbiased estimate of the half-life is calculated using the 0.05 and 0.95 quantiles of $\hat{\alpha}$, calculated again as the time it takes for a unit impulse to dissipate by one half from the occurrence of the initial shock.

${ }^{10}$ Both the Dickey-Fuller and Phillips-Perron median-unbiased measures of persistence and associated confidence intervals can be compared with their least squares counterparts, where the least squares point and interval estimates will (given they are functions of a downwardly-biased $\alpha$ ) tend to understate the actual amount of persistence in shocks to economic time series (see Sections III.A and III.B). 
As with the estimation of $\alpha$, the median-unbiased half-lives and confidence intervals can be interpreted in two ways. Using the Andrews unbiased model-selection rule, there is a 50 percent probability that the confidence interval from zero to the estimated median half-life contains the true half-life of a shock to any given time series, and a 50 percent probability that the confidence interval from the estimated median half-life to infinity contains the true half-life of a shock to any given time series. Alternatively, we can use the 90 percent confidence interval to indicate the range, which has a 90 percent probability of containing the true half-life of a shock to any given time series.

\section{DATa AND EMPIRICAL Results}

In this section we will investigate the persistence properties of the real exchange rate. The theory of relative PPP holds that the exchange rate will be proportional to the ratio of money price levels (including traded and nontraded goods) between countries, which implies that changes in relative price levels will be offset by changes in the exchange rate. By examining the persistence properties of real exchange rates we can determine whether real exchange rates do converge to their equilibrium relative PPP value in the long-run, and thus determine whether PPP is consistent with the data.

The data used to estimate the near unit root model are monthly time series of the real exchange rate obtained from the International Monetary Fund's International Financial Statistics (IFS) over the sample 1979:1 to 2000:1, which gives a total of 253 observations. The definition of the real exchange rate is the real effective exchange rate (REER) based on consumer prices (line $r e c$ ), for which 22 industrial countries were selected. As such, we will examine the behavior of REER based on consumer price indices for the domestic price index, and trade-weighted exchange-rate adjusted price indices for the foreign price index.

REER indices measure how nominal exchange rates, adjusted for price differentials between the home country and its trading partners, have moved over a period of time. The CPI-based REER indicator is calculated as a weighted geometric average of the level of consumer prices in the home country relative to that of its trade partners, expressed in a common currency. The Fund's CPI-based REER indicator (base 1995=100) of country $i$ is defined as $q_{i}=\prod_{j \neq i}\left[\frac{P_{i} R_{i}}{P_{j} R_{j}}\right]^{W_{i j}}$, where $j$ is an index that runs over country $i$ 's trade partner (or competitor) countries; $W_{i j}$ is the competitiveness weight attached by country $i$ to country $j$, which are based on 1988-90 average data on the composition of trade in manufacturing, non-oil primary commodities and tourism services ${ }^{11} ; P_{i}$ and $P_{j}$ are the seasonally-adjusted

${ }^{11} W_{i j}$ can be interpreted as the sum over all markets of a gauge of the degree of competition between producers of country $i$ and $j$, divided by the sum over all markets of a gauge of the degree of competition between producers of country $i$ and all other producers. 
consumer price indices in countries $i$ and $j$; and $R_{i}$ and $R_{j}$ are the nominal exchange rates of countries $i$ and $j$ 's currencies in U.S. dollars. ${ }^{12}$

The REER data for all 22 countries are set out in Figure 1-an increase in the REER series indicates a real appreciation of the country's currency. Several features of the data stand out. First, a cursory inspection of the REER series indicates that most countries have real exchange rates that appear to exhibit symptoms of drift or nonstationarity. There appear to be substantial and sustained deviations from PPP (that is, nonstationarity in the REER). The evolution of REER appears to be a highly persistent, slow-moving process; for most countries the REER does not appear to cycle about any particular equilibrium value, especially for Japan (the general appreciation of its exchange rate is typical of a process with a unit root). Second, sharp movements in the REER during the 1980s and 1990s are a relatively frequent occurrence, especially for countries such as Australia, the Euro Area, New Zealand, the United Kingdom and the United States.

As shown by McDermott (1996), alternative measures of the real exchange rate, such as real bilateral exchange rates based on consumer prices, and the IFS's REER based on normalized unit labor costs, are both highly correlated with the IFS's CPI-based REER index. We analyze effective rather than bilateral real exchange rates as the effective rate measure the international competitiveness of a country against all its trade partners, and helps us avoid potential biases associated with the choice of base country in bilateral real exchange rate analyses. We now describe the results for our analysis of the persistence of parity deviations for the REER series, using both biased least squares and median-unbiased estimators.

${ }^{12}$ The 22 countries (and IFS country numbers) are: Australia (193), Austria (122), Belgium (124), Canada (156), Denmark (128), Euro Area (163), Finland (172), France (132), Germany (134), Iceland (176), Ireland (178), Italy (136), Japan (158), Netherlands (138), New Zealand (196), Norway (142), Portugal (182), Spain (184), Sweden (144), Switzerland (146), and United Kingdom (112), United States (111). A decline (depreciation) in a country's REER index indicates a rise in its international competitiveness (defined as the relative price of domestic tradable goods in terms of foreign tradables). For a detailed explanation and critique of how the Fund's REER indices are constructed, see Zanello and Desruelle (1997) and Wickham (1993). 
Figure 1. Real Effective Exchange Rate, (base 1995=100),

Industrial Countries, 1979:1-2000:1
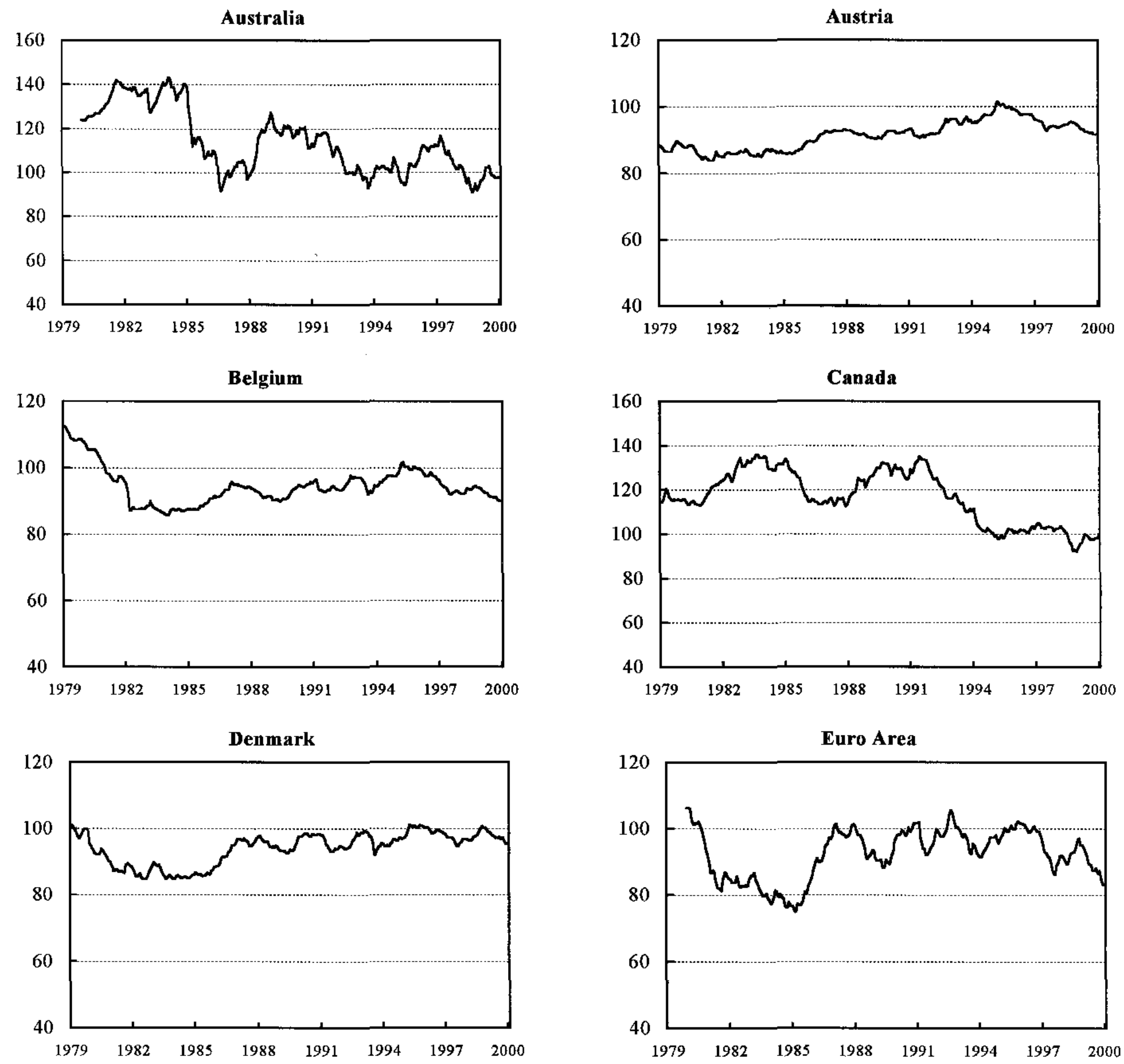
Figure 1 (Continued). Real Effective Exchange Rate, (base 1995=100), Industrial Countries, 1979:1-2000:1
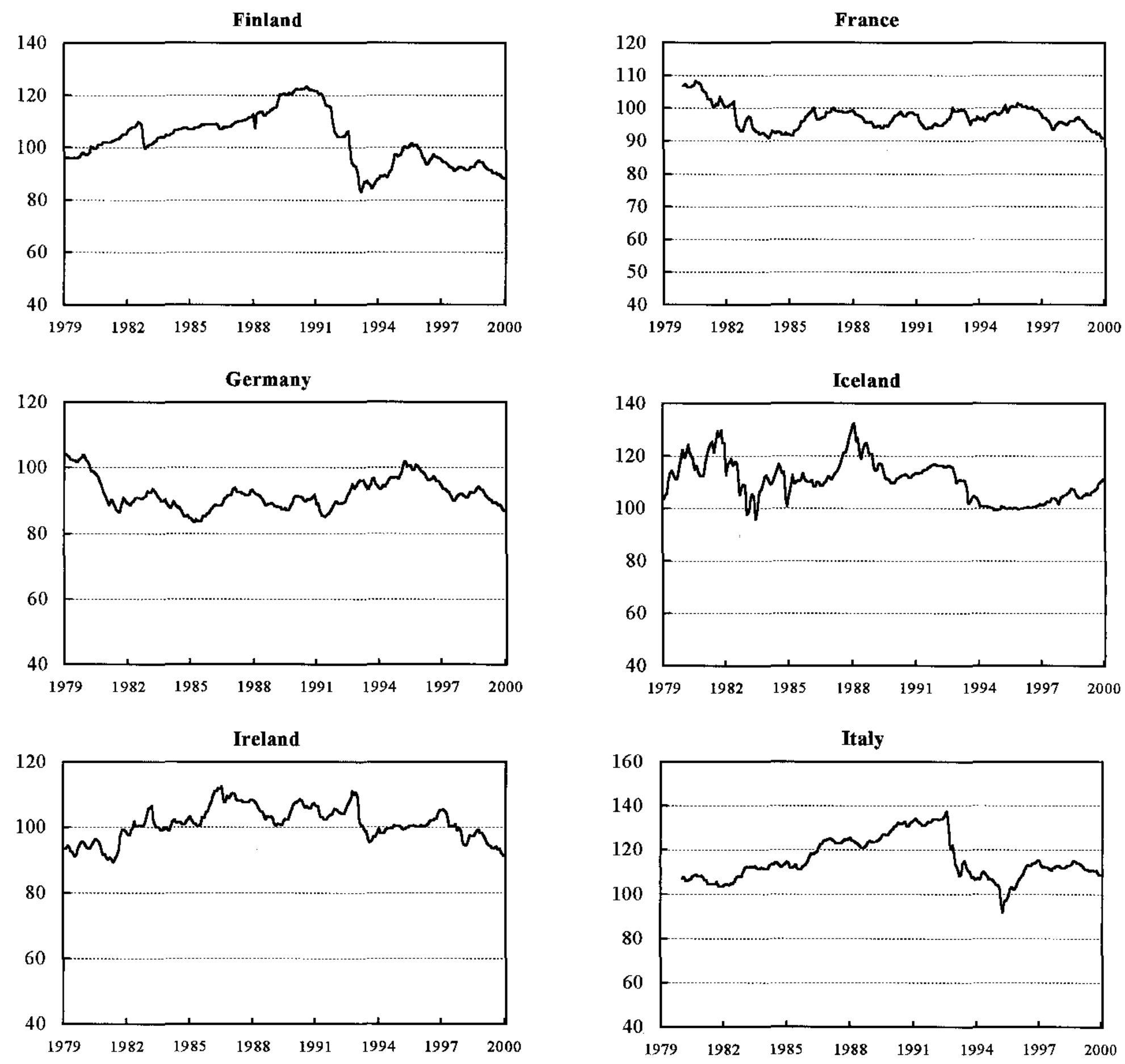
Figure 1 (Continued): Real Effective Exchange Rate, (base 1995=100), Industrial Countries, 1979:1-2000:1
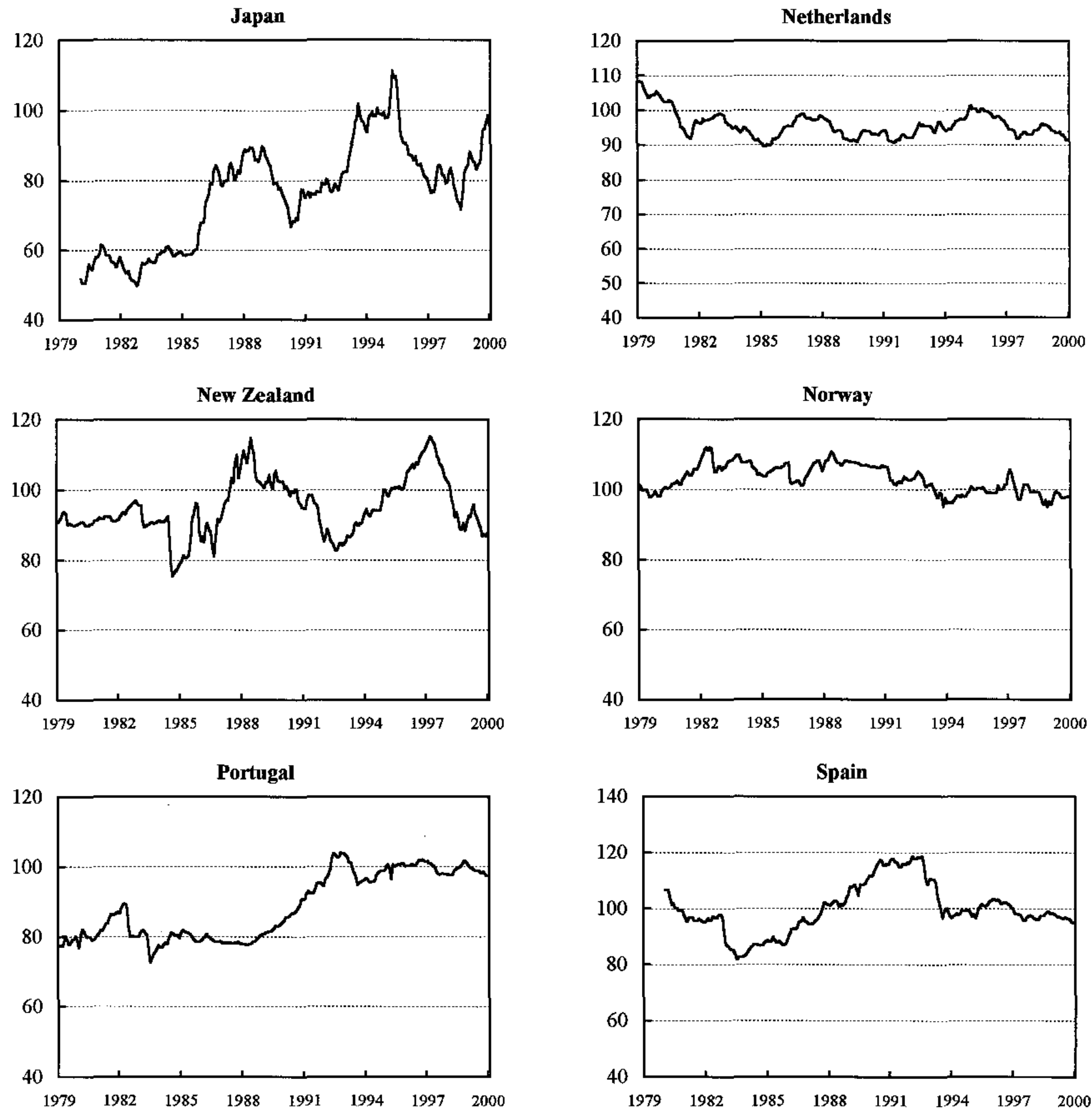
Figure 1 (Concluded): Real Effective Exchange Rate, (base 1995=100), Industrial Countries, 1979:1-2000:1
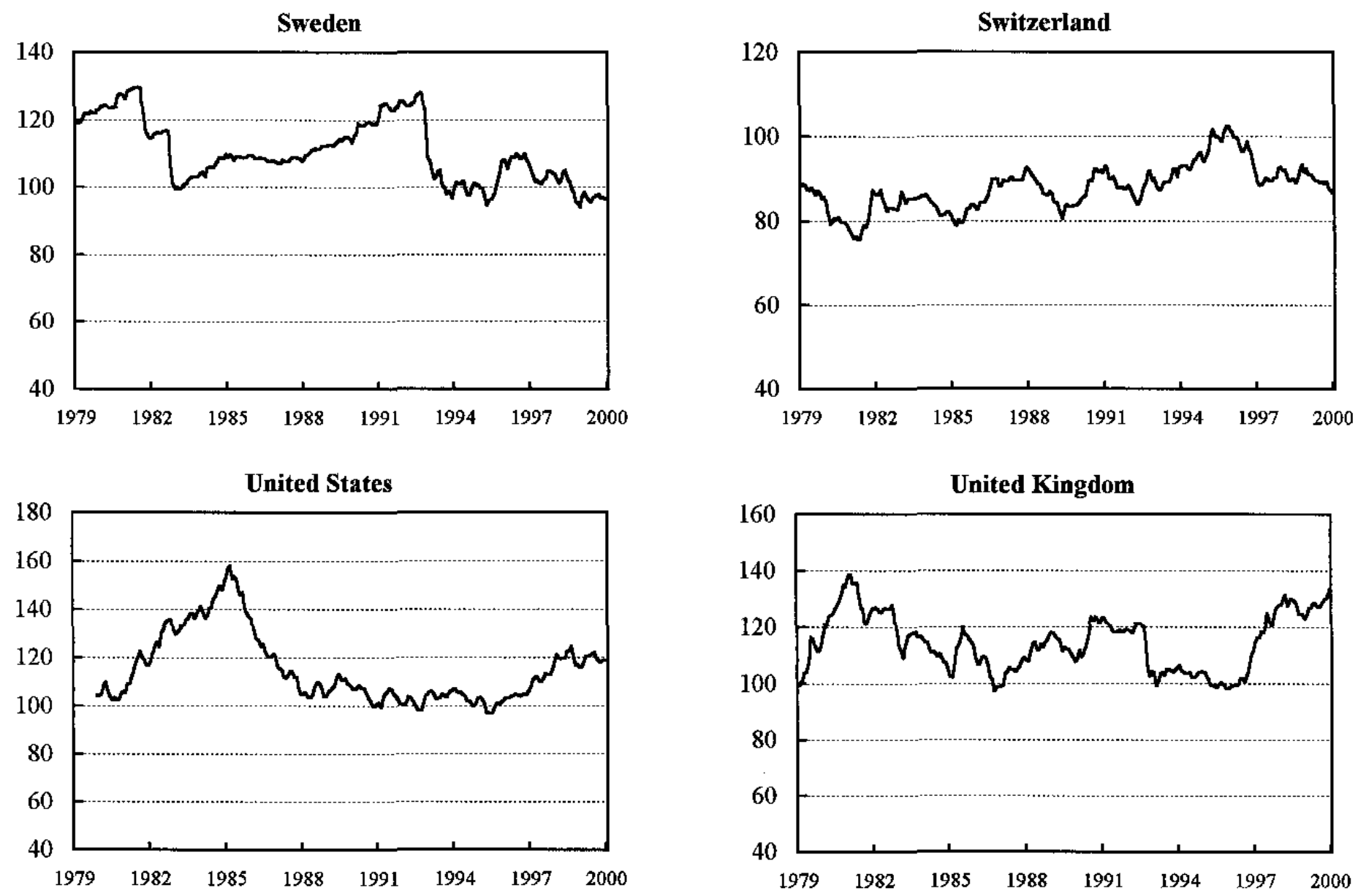

Source: IMF, International Financial Statistics. 


\section{A. Biased Least Squares Estimates of Half-Lives of Parity Reversion}

Table 1 sets out the results for the half-life of the duration of shocks to the REER, which are calculated from the least squares estimates of $\alpha$ in the Dickey-Fuller (DF) regression of equation (1), as set out in Section II. Across all countries, the mean half-life of parity reversion is 51 months and the median half-life is 35 months. ${ }^{13}$ This result is consistent with Rogoff's (1996) consensus of half-lives of parity reversion of between 36 to 60 months (three to five years).

We also report 90 percent confidence intervals for the least squares half-life of PPP deviations, in order to gauge the variability of the persistence of shocks to the real exchange rate. The confidence intervals are quite wide and encompass half-lives that are consistent with PPP holding in the long-run. This indicates that there is a high level of uncertainty about the 'true' value of the half-life of PPP deviations. For seven countries the upper bound of the 90 percent confidence interval is finite, indicating that these countries have finitely-persistent shocks to their real exchange rates. It is important to note that the confidence intervals used here are formed assuming that the estimated autoregressive parameter has a $t$-distribution, which we know to be incorrect, and further biases hypothesis tests toward rejecting the unit root null.

As an example of how to interpret the Table, we take the particular cases of Iceland and Canada. For Iceland, the least squares (LS) estimate of $\alpha$ is 0.95 . Moreover, the time it takes for half of the shock to the REER of Iceland to dissipate is 14 months, while the length of the 90 percent confidence interval for the LS estimate of the half-life of deviations from parity is 8 to 38 months. Accordingly, shocks to the REER of Iceland do not appear to be very persistent, at least relative to the persistence found in other countries' real exchange rates.

For Canada, the LS estimate of $\alpha$ is 0.996 . Moreover, the time it takes for half of the shock to Canada's REER to dissipate is 180 months, while the length of the 90 percent confidence interval for the LS estimate of the half-life of deviations from parity is 41 to $\infty$ months. Accordingly, shocks to the REER of Canada do appear to be very persistent, especially since the lower bound of the 90 percent confidence interval indicates that there is only a 5 percent chance that the true half-life of parity reversion of the REER is shorter than 41 months.

The DF regression results presented in Table 1 do not attempt to account for the presence of serial correlation. Tests for serial correlation carried out on the residuals from the least squares regression of equation (1) indicate that most countries have residuals with serial

${ }^{13}$ These half-life results are comparable to those obtained by Cheung and Lai (2000b) using least squares estimation on monthly bilateral (post-Bretton Woods) dollar real exchange rates, which calculated an average half-life of 3.3 years. 
Table 1. Least Squares Half-Lives of Parity Deviations in Dickey-Fuller Regressions

\begin{tabular}{lcccccc}
\hline Country & $\begin{array}{c}\text { Breusch- } \\
\text { Godfrey }\end{array}$ & White & ARCH & $\alpha$ & $\begin{array}{c}\text { Half-life } \\
\text { (months) }\end{array}$ & $\begin{array}{c}\text { 90 percent CI } \\
\text { (months) }\end{array}$ \\
\hline Australia & & & & & & \\
Austria & $28.4^{*}$ & 0.3 & $13.7^{*}$ & 0.986 & 50 & {$[21, \infty]$} \\
Belgium & $14.4^{*}$ & 5.8 & $5.0^{*}$ & 0.991 & 76 & {$[31, \infty]$} \\
Canada & $19.7^{*}$ & 1.5 & 3.6 & 0.970 & 23 & {$[15,43]$} \\
Denmark & $17.6^{*}$ & 5.2 & 1.8 & 0.996 & 180 & {$[41, \infty]$} \\
Euro area & $20.3^{*}$ & 0.5 & 1.8 & 0.981 & 36 & {$[18, \infty]$} \\
Finland & $31.9^{*}$ & 0.9 & 0.4 & 0.977 & 30 & {$[16, \infty]$} \\
France & $11.5^{*}$ & 0.6 & 2.2 & 0.994 & 110 & {$[33, \infty]$} \\
Germany & $12.4^{*}$ & 4.5 & $14.4^{*}$ & 0.965 & 19 & {$[11,64]$} \\
Iceland & $24.0^{*}$ & 0.8 & 1.0 & 0.972 & 24 & {$[14,74]$} \\
Ireland & 3.6 & $9.6^{*}$ & 1.2 & 0.950 & 14 & {$[8,38]$} \\
Italy & $20.7^{*}$ & $10.2^{*}$ & 0.1 & 0.976 & 28 & {$[14, \infty]$} \\
Japan & $30.2^{*}$ & $12.3^{*}$ & $27.4^{*}$ & 0.987 & 52 & {$[23, \infty]$} \\
Netherlands & $29.0^{*}$ & $20.3^{*}$ & $20.9^{*}$ & 0.988 & 59 & {$[26, \infty]$} \\
New Zealand & $35.0^{*}$ & 0.3 & $4.2^{*}$ & 0.961 & 18 & {$[12,36]$} \\
Norway & $23.8^{*}$ & 0.9 & $22.2^{*}$ & 0.972 & 24 & {$[12,210]$} \\
Portugal & $11.8^{*}$ & $6.4^{*}$ & 1.8 & 0.971 & 24 & {$[12,251]$} \\
Spain & $16.9^{*}$ & 1.1 & $23.5^{*}$ & 0.993 & 102 & {$[38, \infty]$} \\
Sweden & $26.6^{*}$ & 2.1 & $7.2^{*}$ & 0.990 & 71 & {$[28, \infty]$} \\
Switzerland & $31.0^{*}$ & $22.6^{*}$ & $0.8^{*}$ & 0.986 & 49 & {$[21, \infty]$} \\
United Kingdom & $20.4^{*}$ & 0.7 & $4.4^{*}$ & 0.977 & 30 & {$[15, \infty]$} \\
United States & $34.6^{*}$ & 1.1 & $7.6^{*}$ & 0.979 & 33 & {$[16, \infty]$} \\
& $26.5^{*}$ & $25.8^{*}$ & 0.1 & 0.990 & 69 & {$[28, \infty]$} \\
\hline & & & & & & \\
\hline
\end{tabular}

Notes: The results of this table are based on least squares estimation of the Dickey-Fuller regression of equation (1). The half-life is the length of time it takes for a unit impulse to dissipate by half. It is derived using the formula: $\mathrm{HLS}=\mathrm{ABS}(\log (1 / 2) / \log (\alpha))$, where $\alpha$ is the autoregressive parameter. The least squares estimate of the HLS is calculated using the least squares estimate of $\alpha$ in the formula for the HLS. The 90 percent confidence intervals (CI) of the half-life of parity deviations are calculated by inserting $\hat{\alpha} \pm 1.65 \times \operatorname{se}(\hat{\alpha})$ into the HLS formula. The half-lives and the 90 percent confidence intervals are measured in months. Breusch-Godfrey is an LM test of the hypothesis of no serial correlation in the residuals of the AR(I) model of equation (1); the test statistic is distributed as a $\chi^{2}(n)$, where $n$ is the order of the autocorrelations (here $n=2$, so the five percent critical value is 5.99). White is White's (1980) test of the null hypothesis of homoskedasticity; the test statistic is distributed as a $\chi^{2}(s)$, where $s$ is the number of regressors, which here include the square of the regressors only (so $s=2$, and the five percent critical value is 5.99). ARCH is the ARCH LM test for autoregressive conditional heteroskedasticity, where the null is that the coefficient on lagged squared residuals are all zero; the test is distributed as a $\chi^{2}(q)$, where $q$ is the number of squared residuals (here $q=1$, so the five percent critical value is 3.84). An asterisk denotes significance at the five percent level. 
correlation (see column 2 of Table 1). Accordingly, least squares estimates of the Augmented Dickey-Fuller (ADF) regressions, which do account for serial correlation, are set out in Table 2. In examining for the presence of serial correlation, the general-to-specific lag selection procedure of $\mathrm{Ng}$ and Perron (1995) and Hall (1994) is used, with the maximum lag set to $14 .{ }^{14}$ For all countries at least one lag $(p=2)$ of the first difference of the REER are significant, which ensures that the ADF half-lives will differ from the DF half-lives. The ADF half-lives are typically shorter in duration than those derived from the DF regression, ranging from 17 months (France and Iceland) to 93 months (Portugal). Across all countries, the mean half-life of parity reversion is 38 months and the median half-life is 31 months. While for several countries the 90 percent confidence interval is narrower than for the DF regression (such as New Zealand and Norway), in several cases the variability of shocks to the REER is so wide as to include infinity as the upper bound of the confidence interval (such as Japan and the United States). ${ }^{15}$

The ADF regressions presented in Table 2 do not attempt to account for the presence of heteroskedasticity. Tests for heteroskedasticity carried out on the residuals from the least squares regression of equation (1) indicate that the majority of countries have residuals with heteroskedasticity (see columns 3 and 4 of Table 1). Accordingly, to account for heteroskedasticity, and to allow for the presence of serial correlation (including movingaverage error structures), the results of Phillips-Perron (PP) regressions, which are valid in the presence of heteroskedasticity, are presented in Table 3. The duration of PP half-lives are typically lower again than those derived from the ADF and DF regressions, ranging from 12 months (Netherlands and Iceland) to 86 months (Canada). Across all countries, the mean half-life of parity reversion from the PP regression is 31 months and the median half-life is 22 months. The 90 percent confidence intervals of the half-lives of deviations from parity are typically tighter for those countries with finite upper bounds than those derived from the $\mathrm{ADF}$ and DF regressions, yet continue to encompass infinity for most of those countries that had such a finding for the $\mathrm{ADF}$ regressions.

Broadly, the three least squares results of Tables 1-3 indicate that across all countries the median half-life is finite, with a mean length of about three years, and a lower bound on the confidence intervals for the true half-lives of about two years. However, the upper bound of the confidence interval for many REER is greater than five years (and in many cases is infinity).

${ }^{14}$ Starting with the maximum lag, first-differences of the logarithm of the REER $\left(q_{t}\right)$ were sequentially removed from the AR model until the last lag was statistically significant (at the 5 percent level). At that point all lag lengths smaller than or equal to $p-1$ are included in the $\operatorname{AR}(p)$ regression of equation (2).

${ }^{15}$ Consistent with Papell (1997), we find that accounting for serial correlation in the disturbances weakens the evidence against a null hypothesis of a unit root in the real exchange rate series, as the point estimates of the autoregressive parameter are typically lower in the $\operatorname{AR}(p)$ case than for the $\operatorname{AR}(1)$ regression. 
Table 2. Least Squares Half-Lives of Parity Deviations in Augmented Dickey-Fuller Regressions

\begin{tabular}{lcccc}
\hline Country & $\boldsymbol{p}$ & $\boldsymbol{\alpha}$ & $\begin{array}{c}\text { Half-life } \\
\text { (months) }\end{array}$ & $\begin{array}{c}\text { 90 percent CI } \\
\text { (months) }\end{array}$ \\
\hline Australia & & & & \\
Austria & 2 & 0.982 & 41 & {$[20, \infty]$} \\
Belgium & 4 & 0.989 & 67 & {$[30, \infty]$} \\
Canada & 11 & 0.974 & 29 & {$[19,65]$} \\
Denmark & 2 & 0.989 & 66 & {$[34, \infty]$} \\
Euro area & 2 & 0.978 & 33 & {$[19,155]$} \\
Finland & 11 & 0.971 & 25 & {$[15,78]$} \\
France & 5 & 0.984 & 47 & {$[28, \infty]$} \\
Germany & 8 & 0.964 & 17 & {$[16,43]$} \\
Iceland & 9 & 0.943 & 23 & {$[11,36]$} \\
Ireland & 5 & 0.967 & 17 & {$[22,88]$} \\
Italy & 4 & 0.982 & 40 & {$[28, \infty]$} \\
Japan & 12 & 0.986 & 53 & {$[13,35]$} \\
Netherlands & 2 & 0.961 & 19 & {$[12,65]$} \\
New Zealand & 4 & 0.964 & 21 & {$[39, \infty]$} \\
Norway & 2 & 0.964 & 20 & {$[28, \infty]$} \\
Portugal & 2 & 0.992 & 93 & {$[19,250]$} \\
Spain & 7 & 0.987 & 57 & {$[14,85]$} \\
Sweden & 2 & 0.979 & 35 & {$[14,80]$} \\
Switzerland & 4 & 0.970 & 24 & {$[28, \infty]$} \\
United Kingdom & 4 & 0.969 & 24 & \\
United States & 2 & 0.987 & 58 & \\
& & & & \\
\hline
\end{tabular}

Notes: The results of this table are based on least squares estimation of the Augmented Dickey-Fuller regression of equation (2). The half-life for $\operatorname{AR}(p)$ models is calculated from the impulse response functions (equation (5)), and is defined as the time it takes for a unit impulse to dissipate by one half from the occurrence of the initial shock. Similarly, the 90 percent confidence interval (CI) is calculated using the 0.05 and 0.95 quantiles, calculated again as the time it takes for a unit impulse to dissipate by one half from the occurrence of the initial shock. The half-lives of parity deviations and the 90 percent confidence intervals are measured in months. In examining for the presence of serial correlation, the general-to-specific lag selection procedure of $\mathrm{Ng}$ and Perron (1995) and Hall (1994) is used, with the maximum lag $(p)$ set to 14 . First-differences of the REER $\left(q_{t}\right)$ were sequentially removed from the AR model until the last ( $p$ th) lag was statistically significant (at the 5 percent level). 
Table 3. Least Squares Half-Lives of Parity Deviations in Phillips-Perron Regressions

\begin{tabular}{|c|c|c|c|c|}
\hline Country & $b$ & $\alpha$ & $\begin{array}{c}\text { Half-life } \\
\text { (months) }\end{array}$ & $\begin{array}{c}90 \text { percent CI } \\
\text { (months) }\end{array}$ \\
\hline Australia & 8 & 0.979 & 33 & {$[15, \infty]$} \\
\hline Austria & 6 & 0.987 & 53 & {$[24, \infty]$} \\
\hline Belgium & 7 & 0.963 & 18 & {$[12,37]$} \\
\hline Canada & 7 & 0.992 & 86 & {$[29, \infty]$} \\
\hline Denmark & 7 & 0.971 & 23 & {$[12,117]$} \\
\hline Euro area & 9 & 0.959 & 17 & {$[10,58]$} \\
\hline Finland & 6 & 0.989 & 62 & {$[24, \infty]$} \\
\hline France & 6 & 0.953 & 14 & {$[9,39]$} \\
\hline Germany & 8 & 0.959 & 17 & {$[10,44]$} \\
\hline Iceland & 4 & 0.946 & 12 & {$[8,32]$} \\
\hline Ireland & 7 & 0.958 & 16 & {$[9,65]$} \\
\hline Italy & 8 & 0.978 & 31 & {$[15, \infty]$} \\
\hline Japan & 9 & 0.982 & 37 & {$[18, \infty]$} \\
\hline Netherlands & 9 & 0.945 & 12 & {$[8,24]$} \\
\hline New Zealand & 7 & 0.959 & 17 & {$[9,63]$} \\
\hline Norway & 6 & 0.961 & 18 & {$[10,77]$} \\
\hline Portugal & 6 & 0.991 & 77 & {$[31, \infty]$} \\
\hline Spain & 8 & 0.983 & 41 & {$[19, \infty]$} \\
\hline Sweden & 9 & 0.973 & 25 & {$[13, \infty]$} \\
\hline Switzerland & 7 & 0.965 & 20 & {$[11,94]$} \\
\hline United Kingdom & 9 & 0.959 & 16 & {$[9,65]$} \\
\hline United States & 8 & 0.983 & 41 & {$[19, \infty]$} \\
\hline
\end{tabular}

Notes: The results of this table are based on least squares estimation of the Phillips-Perron (PP) regression of equation (1). The half-life is the length of time it takes for a unit impulse to dissipate by half from the occurrence of the initial shock. It is derived using the formula: $\mathrm{HLS}=\mathrm{ABS}(\log (1 / 2) / \log (\alpha))$, where $\alpha$ is the autoregressive parameter. The PP estimate of the HLS is calculated using the PP estimate of $\alpha$ in the formula for the HLS. The 90 percent confidence intervals $(\mathrm{Cl})$ of the half-life of parity deviations are calculated by inserting $\hat{\alpha}+1.65 \times \operatorname{se}(\hat{\alpha})$ into the HLS formula, where $\operatorname{se}(\hat{\alpha})$ is calculated using a long-run variance estimator. The half-lives and the 90 percent confidence intervals are measured in months. To control the amount of serial dependence allowed in the Phillips-Perron regression, the bandwidth parameter needs to be selected-we have used the automatic bandwidth selector of Andrews (1991), where the bandwidth (number of periods to the nearest integer of serial correlation included) is indicated by $b$. 


\section{B. Median-Unbiased Estimates of Half-Lives of Parity Reversion}

The half-lives of PPP deviations calculated above (using the least squares estimator) are reasonably close to Rogoff's (1996) consensus of three to five years (36 to 60 months). However, as noted in Section II above, the estimator of the autoregressive parameter in each of the DF, ADF and PP regressions is always biased downward. As a result, the above calculations of the duration of deviations from PPP are likely to be biased downward (and in favor of finding that PPP holds in the REER data). Consequently, we remove this bias by calculating median-unbiased point estimates and confidence intervals for the autoregressive parameter in equation (1) and equation (2). ${ }^{16}$

Median-unbiased estimates of the half-life of PPP deviations for the DF regressions are set out in Table 4. In comparison with the median-unbiased estimates of $\alpha$ in DF regressions, the least squares estimates of $\alpha$ are biased downward by between 0.004 and 0.016 (see Table 1). While this is a small difference in absolute terms, it has important implications for the half-life measures of the persistence of the REER. The median-unbiased point estimates of the half-lives are much greater than their least squares counterparts for every country, with 10 of the countries having a median half-life of infinity. Across all countries, the median half-life of parity reversion is 180 months, clearly exceeding the least squares AR(1) median half-life of 35 months. This implies a rate of parity reversion of only 5 percent per year, rather than the 21 percent per year calculated using biased DF methods. In addition, as the median-unbiased estimates of $\alpha$ in the DF regression take account of the asymmetry of the distribution of $\hat{\alpha}$, the 90 percent confidence intervals for the medianunbiased estimates of half-lives of parity reversion are typically much wider than for their LS

\footnotetext{
${ }^{16}$ Median-unbiased estimates (and confidence intervals) of the half-life of a shock (for $T=253$ observations (1979:1-2000:1)) were determined using quantile functions of $\hat{\alpha}$ generated by: numerical simulation (using 10,000 iterations), following the method suggested by Appendix B of Andrews (1993) for the DF regression of equation (1) (see Table 4); numerical simulation (using 10,000 iterations), following the method suggested by McDermott (1996) for the PP regression of equation (1) (see Table 6); and by numerical simulation (using 2,500 iterations), following the method suggested by Andrews and Chen (1994) for the ADF regression of equation (2) (see Table 5).
} 
Table 4. Median Unbiased Half-Lives of Parity Deviations in Dickey-Fuller Regressions

\begin{tabular}{lccc}
\hline Country & $\boldsymbol{\alpha}$ & $\begin{array}{c}\text { Half-life } \\
\text { (months) }\end{array}$ & $\begin{array}{c}\text { 90 percent CI } \\
\text { (months) }\end{array}$ \\
\hline Australia & & & {$[31, \infty]$} \\
Austria & 1.000 & $\infty$ & {$[47, \infty]$} \\
Belgium & 1.000 & $\infty$ & {$[15, \infty]$} \\
Canada & 0.984 & 44 & {$[115, \infty]$} \\
Denmark & 1.000 & $\infty$ & {$[22, \infty]$} \\
Euro area & 0.997 & 221 & {$[19, \infty]$} \\
Finland & 0.993 & 92 & {$[69, \infty]$} \\
France & 1.000 & $\infty$ & {$[13, \infty]$} \\
Germany & 0.979 & 32 & {$[16, \infty]$} \\
Iceland & 0.987 & 18 & {$[9, \infty]$} \\
Ireland & 0.963 & 79 & {$[18, \infty]$} \\
Italy & 0.991 & $\infty$ & {$[33, \infty]$} \\
Japan & 1.000 & $\infty$ & {$[12, \infty]$} \\
Netherlands & 1.000 & 27 & {$[16, \infty]$} \\
New Zealand & 0.974 & 52 & {$[15, \infty]$} \\
Norway & 0.987 & 48 & {$[60, \infty]$} \\
Portugal & 0.986 & $\infty$ & {$[43, \infty]$} \\
Spain & 1.000 & $\infty$ & {$[31, \infty]$} \\
Sweden & 1.000 & $\infty$ & {$[19, \infty]$} \\
Switzerland & 1.000 & 89 & {$[43, \infty]$} \\
United Kingdom & 0.992 & 138 & \\
United States & 0.995 & $\infty$ & \\
& 1.000 & & \\
\hline
\end{tabular}

Notes: The results of this table are based on the median-unbiased estimates of the Dickey-Fuller regression of equation (1), as given by Andrews (1993). The half-life is the length of time it takes for a unit impulse to dissipate by half. It is derived using the formula: HLS $=\operatorname{ABS}(\log (1 / 2) / \log (\alpha))$, where $\alpha$ is the autoregressive parameter. The median-unbiased estimate of the HLS is calculated using the median-unbiased estimate of $\alpha$ in the formula for the HLS. Similarly, the 90 percent confidence intervals (CI) of the half-life of parity deviations are derived using the 0.05 and 0.95 quantiles of the median-unbiased estimate of $\hat{\alpha}$ in the formula for the HLS. The quantile functions of $\hat{\alpha}$ were generated by numerical simulation (using 10,000 iterations) for $T=253$ observations. The half-lives and the 90 percent confidence intervals are measured in months. 
counterparts in Table 1, and all countries in Table 4 have an upper bound to the confidence interval of the half-lives which embrace infinity. ${ }^{17}$

The results in Table 4 indicate that, using the Andrews unbiased model-selection rule, 12 of the countries are subject to REER shocks that are finitely-persistent, while 10 of the countries experience permanent shocks to their REER series. The interpretation of this rule is that for any given country there is a 50 percent probability that the confidence interval from zero to the estimated median half-life contains the true half-life of shocks to its REER, and a 50 percent probability that the confidence interval from the estimated median half-life to infinity contains the true half-life of shocks to its REER. Let us again take the examples of Iceland (short-lived half-life) and the Canada (infinite half-life). While there is a 50 percent probability that the confidence interval from zero to 18 months contains the true half-life of shocks to the REER of Iceland, there is also a 50 percent probability that the confidence interval from 18 months to infinity contains the true half-life of shocks to the REER of Iceland. For Canada, while there is a 50 percent probability that the confidence interval with a finite upper bound contains the true half-life of shocks to its REER, there is a 50 percent probability that the true half-life of shocks to its REER will be infinite (Table 4).

Using the alternative loss function implicit in conventional two-sided (level 0.10 ) hypothesis tests, there is another way to interpret our findings. Again, taking the examples of Iceland and Canada, we find that the estimated 90 percent confidence intervals of the halflife of deviations from parity range from 9 months to infinity, and from 115 months to infinity, respectively (Table 4). There is a 90 percent probability that the above confidence intervals contain the true half-life of shocks to each country's REER. Accordingly, there is a 5 percent probability that the confidence interval from zero to 9 months contains the true half-life of shocks to the REER of Iceland, and a 95 percent probability that the confidence interval from 9 months to infinity contains the true half-life of shocks to the REER of Iceland. As found in the biased DF regression, shocks to the REER of Iceland do not appear to be very persistent. In contrast, while there is a 5 percent probability that the confidence interval from zero to 115 months contains the true half-life of shocks to the REER of Canada, there is a 95 percent probability that the confidence interval from 115 months to infinity contains the true half-life of shocks to the REER of Canada. Using the Andrews unbiased

${ }^{17}$ Our results for the median-unbiased Dickey-Fuller regression are similar to those of Andrews (1993), who calculated point and interval estimates of the half-life of monthly bilateral dollar real exchange rates for several industrial countries over the period 1973 to 1988. He found that, using least squares, the half life of PPP deviations for each real exchange rate was finite, with an average half life of about 31 months. However, using the median-unbiased procedure (for an AR(1) model) only three of the eight real exchange rates had finite half-lives of PPP deviations, with an average half life of about 60 months. The remaining five exhibited permanent parity deviations. Similarly, while all of Andrews' median-unbiased lower bounds of the 90 percent confidence interval were less than 24 months (as is the case for the majority of countries in the present study), the upper bounds were all infinite (as is the case in this study). 
model-selection rule, the unit root model is the most appropriate representation of the Canadian REER, and so shocks to the Canadian REER are best viewed as being permanent.

The median-unbiased estimates of the autoregressive parameter in ADF regressions control for serial correlation, and are reported in Table 5. Again, in comparison with their least squares counterparts of Table 2, the median half-lives of deviations from PPP are typically much longer, ranging from 20 months (Iceland) to infinity (Canada and the United States, among others). Across all countries, the median half-life of parity reversion is 53 months, in excess of the least squares $\operatorname{AR}(p)$ median half-life of 31 months. This implies a rate of parity reversion of only 15 percent per year, rather than the 24 percent per year calculated using biased ADF methods. Similarly, the median-unbiased confidence intervals are much wider than their least squares counterparts. ${ }^{18}$ The Andrews unbiased modelselection rule indicates that all but 6 of the 22 countries have finitely-persistent shocks to their REER, which is consistent with the slow reversion of REER to parity. However of all 22 countries, only Iceland produced a 90 percent confidence interval for the half-life of deviation from parity that did not include infinity. Taking the United Kingdom as an example, while there is a 50 percent probability that the confidence interval from zero to 29 months contains the true half-life of shocks to its REER, there is also a 50 percent probability that the confidence interval from 29 months to infinity contains the true half-life. In addition, while there is a 5 percent probability that the confidence interval from zero to 17 months contains the true half-life of shocks to the REER of the United Kingdom, there is a 95 percent probability that the confidence interval from 17 months to infinity contains the true half-life (Table 5). The width of this confidence interval for the half-life indicates there is a great deal of uncertainty as to the duration of the true half-life of parity reversion of the United Kingdom's REER.

The regression that corrects for the least-squares downward bias, and controls for serial correlation and heteroskedasticity is the median-unbiased PP regression, the results of which are reported in Table 6 . Across all countries, the median half-life of parity reversion is 43 months, clearly exceeding the PP median half-life of 22 months. This implies a rate of parity reversion of only 18 percent per year, rather than the 31 percent per year calculated using biased PP methods. ${ }^{19}$

${ }^{18}$ Murray and Papell (2000) follow Andrews and Chen (1994) in calculating medianunbiased estimates of half-lives for bilateral dollar real exchange rates. They find that the median half-life is about 3 years, but with confidence intervals that are typically so large that the point estimates of half-lives from ADF regressions provide virtually no information regarding the size of the half-lives.

${ }^{19}$ Interestingly, the broad pattern found in the biased least squares estimates of half-lives of parity reversion (reported in Tables 1-3) is also found for the median-unbiased estimates of half-lives of parity reversion (reported in Tables 4-6), with the estimation method which controls for serial correlation and heteroscedasticity (the PP regression) yielding the smallest half lives. 
Table 5. Median Unbiased Half-Lives of Parity Deviations in Augmented Dickey-Fuller Regressions

\begin{tabular}{lcccc}
\hline Country & $\boldsymbol{p}$ & $\boldsymbol{\alpha}$ & $\begin{array}{c}\text { Half-life } \\
\text { (months) }\end{array}$ & $\begin{array}{c}\text { 90 percent CI } \\
\text { (months) }\end{array}$ \\
\hline Australia & 3 & 0.993 & 98 & {$[22, \infty]$} \\
Austria & 2 & 1.000 & $\infty$ & {$[37, \infty]$} \\
Belgium & 4 & 0.982 & 41 & {$[20, \infty]$} \\
Canada & 11 & 1.000 & $\infty$ & {$[40, \infty]$} \\
Denmark & 2 & 0.985 & 64 & {$[20, \infty]$} \\
Euro area & 2 & 0.981 & 39 & {$[17, \infty]$} \\
Finland & 11 & 0.993 & 94 & {$[32, \infty]$} \\
France & 5 & 0.969 & 23 & {$[11, \infty]$} \\
Germany & 8 & 0.970 & 26 & {$[16, \infty]$} \\
Iceland & 9 & 0.950 & 20 & {$[11,65]$} \\
Ireland & 5 & 0.980 & 36 & {$[13, \infty]$} \\
Italy & 4 & 0.993 & 97 & {$[28, \infty]$} \\
Japan & 12 & 1.000 & $\infty$ & {$[28, \infty]$} \\
Netherlands & 2 & 0.969 & 23 & {$[13, \infty]$} \\
New Zealand & 4 & 0.972 & 26 & {$[14, \infty]$} \\
Norway & 2 & 0.972 & 26 & {$[14, \infty]$} \\
Portugal & 2 & 1.000 & $\infty$ & {$[47, \infty]$} \\
Spain & 7 & 1.000 & $\infty$ & {$[39, \infty]$} \\
Sweden & 2 & 0.985 & 64 & {$[24, \infty]$} \\
Switzerland & 4 & 0.981 & 39 & {$[17, \infty]$} \\
United Kingdom & 4 & 0.975 & 29 & {$[17, \infty]$} \\
United States & 2 & 1.000 & $\infty$ & {$[37, \infty]$} \\
& & & & \\
\hline & & & &
\end{tabular}

Notes: The results of this table are based on the median-unbiased estimates of the Augmented Dickey-Fuller regression of equation (2), as given by Andrews and Chen (1994). The median half-life for $\operatorname{AR}(p)$ models is calculated from the impulse response functions (equation (5)), and is defined as the time it takes for a unit impulse to dissipate by one half from the occurrence of the initial shock. Similarly, the 90 percent confidence interval (CI) is calculated using the 0.05 and 0.95 quantiles, calculated again as the time it takes for a unit impulse to dissipate by one half from the occurrence of the initial shock. The quantile functions of $\hat{\alpha}$ were generated by numerical simulation (using 2,500 iterations). The half-lives of parity deviations and the 90 percent confidence intervals are measured in months. In examining for the presence of serial correlation, the general-to-specific lag selection procedure of $\mathrm{Ng}$ and Perron (1995) and Hall (1994) is used, with the maximum lag $(p)$ set to 14. Firstdifferences of the REER $\left(q_{t}\right)$ were sequentially removed from the AR model until the last ( $p$ th) lag was statistically significant (at the 5 percent level). 
The Andrews unbiased model-selection rule indicates that all but 7 of the 22 countries have finitely-persistent shocks to their REER, which is consistent with the slow reversion of REER to parity. All countries have 90 percent confidence intervals for their half-lives of deviations from parity that embrace infinity. Taking the United States as an example, while there is a 5 percent probability that the confidence interval from zero to 26 months contains the true half-life of shocks to its REER, there is a 95 percent probability that the confidence interval from 26 months to infinity contains the true half-life (Table 6). Using the Andrews unbiased model-selection rule, the unit root model is the most appropriate representation of the United States REER, and so shocks to its REER are best viewed as being permanent.

In contrast to the above results, Taylor (2000) argues that there are two sources of upward bias in the estimation of the speed of parity reversion. First, temporal aggregation bias, whereby sampling data at low frequencies does not allow one to identify a highfrequency adjustment process. Second, the linear AR(1) specification of the standard (Dickey-Fuller) unit root model assumes that reversion occurs monotonically, regardless of how far the process is from parity. However, as the present paper uses monthly REER data, the temporal aggregation bias is likely to be minimal. In addition, our use of $\operatorname{AR}(p)$ models allows for shocks to the REER to not necessarily decline at a constant rate. Taylor finds that when both sources of upward bias are present, then the estimated half-life can be between 1.5 to 2.2 times the true half-life, for the case when monthly averaged data is being used to estimate a monthly (or greater) half-life nonlinear threshold autoregressive process. Taylor (2000, p.19) also acknowledges that month-to-month variation in nominal exchange rates is likely to dwarf the variation in prices, and that the former are accurately measured in the IFS data. In comparison, the results from Tables 1 versus Tables 4 indicates that for the AR(1) model, the estimated half-life can be about 0.2 times the true half-life, clearly an impact much larger than either of Taylor's upward biases.

\section{What Might Be Causing Highly-Persistent Deviations from PPP?}

As noted by Rogoff (1996), in tens of dozens of studies, researchers have repeatedly found long-lived half-lives for shocks to real (CPI-based) exchange rates. While the persistence of innovations to real exchange rates may be consistent with a dominance of real shocks relative to monetary shocks, the frequency of real shocks is nowhere near large enough to generate the observed high volatility of real exchange rates. However, Obstfeld and Rogoff (2000) note that if monetary and financial shocks are driving the volatility of nominal and real exchange rates, what sort of nominal rigidity can explain the observed longlived deviations from PPP? Several recent attempts to rationalize this puzzle have been made in the literature, yet most of them take as their starting point the consensus half-life of parity deviations of Rogoff's (1996) 3 to 5 years, which we have demonstrated is biased downward.

In the absence of nominal rigidities, mean reversion of real exchange rates should occur very rapidly. Monetary models of the exchange rate yield the implication that the halflives of deviations from PPP should be short-lived-implausibly sticky nominal wages and 
Table 6. Median Unbiased Half-Lives of Parity Deviations in Phillips-Perron Regressions

\begin{tabular}{lcccc}
\hline Country & $\boldsymbol{b}$ & $\boldsymbol{\alpha}$ & $\begin{array}{c}\text { Half-life } \\
\text { (months) }\end{array}$ & $\begin{array}{c}\text { 90 percent CI } \\
\text { (months) }\end{array}$ \\
\hline Australia & 8 & 0.996 & 156 & {$[21, \infty]$} \\
Austria & 6 & 1.000 & $\infty$ & {$[34, \infty]$} \\
Belgium & 7 & 0.978 & 31 & {$[12, \infty]$} \\
Canada & 7 & 1.000 & $\infty$ & {$[59, \infty]$} \\
Denmark & 7 & 0.987 & 52 & {$[15, \infty]$} \\
Euro area & 9 & 0.973 & 26 & {$[11, \infty]$} \\
Finland & 6 & 1.000 & $\infty$ & {$[41, \infty]$} \\
France & 6 & 0.967 & 21 & {$[10, \infty]$} \\
Germany & 8 & 0.973 & 26 & {$[11, \infty]$} \\
Iceland & 4 & 0.960 & 17 & {$[9, \infty]$} \\
Ireland & 7 & 0.972 & 25 & {$[11, \infty]$} \\
Italy & 8 & 0.994 & 124 & {$[20, \infty]$} \\
Japan & 9 & 1.000 & $\infty$ & {$[24, \infty]$} \\
Netherlands & 9 & 0.959 & 16 & {$[8, \infty]$} \\
New Zealand & 7 & 0.973 & 26 & {$[11, \infty]$} \\
Norway & 6 & 0.976 & 28 & {$[12, \infty]$} \\
Portugal & 6 & 1.000 & $\infty$ & {$[52, \infty]$} \\
Spain & 8 & 1.000 & $\infty$ & {$[26, \infty]$} \\
Sweden & 9 & 0.989 & 62 & {$[17, \infty]$} \\
Switzerland & 7 & 0.980 & 34 & {$[13, \infty]$} \\
United Kingdom & 9 & 0.973 & 26 & {$[11, \infty]$} \\
United States & 8 & 1.000 & $\infty$ & {$[26, \infty]$} \\
& & & & \\
\hline
\end{tabular}

Notes: The results of this table are based on the median-unbiased estimates of the Phillips-Perron regression of equation (1). The half-life is the length of time it takes for a unit impulse to dissipate by half from the occurrence of the initial shock. It is derived using the formula: $\mathrm{HLS}=\mathrm{ABS}(\log (1 / 2) / \log (\alpha))$, where $\alpha$ is the autoregressive parameter. The median-unbiased estimate of the HLS is calculated using the median-unbiased estimate of $\alpha$ in the formula for the HLS. Similarly, the 90 percent confidence intervals (CI) of the half-life of parity deviations are derived using the 0.05 and 0.95 quantiles of the median-unbiased estimate of $\hat{\alpha}$ in the formula for the HLS. The quantile functions of $\hat{\alpha}$ were generated by numerical simulation (using 10,000 iterations) for $T=253$ observations. The half-lives and the 90 percent confidence intervals are measured in months. To control the amount of serial dependence allowed in the Phillips-Perron regression, the bandwidth parameter needs to be selected - we have used the automatic bandwidth selector of Andrews (1991), where the bandwidth (number of periods to the nearest integer of serial correlation included) is indicated by $b$. Following Andrews and Chen (1994), in calculating the median-unbiased estimates of $\alpha$, the parameter space is restricted to $(-1,1]$. 
prices are needed to generate long-lived persistence of real exchange rates. To account for the observed high degree of persistence we would need to appeal to other open economy models which contain features likely to engender long-lived deviations from PPP, such as: persistent differences in productivity growth across countries (Froot and Rogoff (1995)); intertemporal consumption smoothing of consumption goods (Rogoff (1992)); monopolistic producers (pricing to market) and nominal rigidities (Bergin and Feenstra (1999)); and the presence of trade costs (Obstfeld and Rogoff (2000)).

\section{CONCLUSION}

This paper has re-examined whether purchasing power parity (PPP) holds during the post-Bretton Woods period, by investigating the time series properties of the real effective exchange rate for 22 industrial countries. The theory of relative PPP holds that the exchange rate will be proportional to the ratio of money price levels (including traded and nontraded goods) between countries, which implies that changes in relative price levels will be offset by changes in the exchange rate. In assessing whether real exchange rates do converge to their equilibrium relative PPP value in the long-run, we eschew undertaking hypothesis tests of whether real exchange rates follow a unit root process. Instead, we follow Andrews (1993) and use point and interval statistics of the half-life of deviations from parity as our preferred measure of the persistence of real exchange rate shocks.

Univariate studies of the hypothesis of unit roots in real exchange rates have yielded consensus point estimates of the half-life of deviations from purchasing power parity of between 3 to 5 years (Rogoff (1996)). Using standard (least squares) biased estimation of unit root models, we replicate the consensus finding in the literature. However, using median-unbiased estimation techniques that remove the downward bias of standard autoregressive estimators, we find that the half-lives of parity reversion are longer than the consensus point estimate, with the REER of several countries displaying permanent deviations from parity. The cross-country average of half-lives of deviations from parity range between 4 to 15 years, depending on the assumptions made about the type of serial correlation and heteroskedasticity in real exchanges rates.

If conventional unit root statistics are used to test the null hypothesis of no PPP we cannot reject the null using post-Bretton Woods data. However, failure to reject the null hypothesis conveys little information as to the validity of PPP, as such a failure may occur either because PPP is true, or because there is too much uncertainty as to the rate of reversion to purchasing power parity. Using the regression that allows for the broadest error structure, for 15 countries in our sample the failure to reject the unit root null hypothesis cannot be construed as providing evidence in favor of the null (and against PPP), because their confidence intervals of half-lives are too wide and encompass half-lives that are consistent with PPP holding in the long-run. 
In contrast, using the Andrews median-unbiased selection rule we can be more definitive about the our willingness to accept the null (of no PPP) in the post-Bretton Woods period. We find that at least 7 countries have infinite median half-lives of parity reversion, indicating that there is a better than even chance that real exchange rate shocks are permanent, and so PPP does not hold in these countries. Moreover, for these countries the lower bound of the 90 percent confidence intervals for their half-lives is greater than two years. Such high persistence of shocks to the real exchange rate cannot be explained by overshooting models that rely on nominal rigidities in wages and goods prices, as in such models one would expect substantial convergence of real exchange rates to PPP over a period of one to two years. 


\section{References}

Abuaf, Niso and Phillipe Jorion, (1990), "Purchasing Power Parity in the Long Run," Journal of Finance, Vol. 45, pp. 157-74.

Andrews, Donald, (1991), "Heteroskedasticity and Autocorrelation Consistent Covariance Matrix Estimation," Econometrica, Vol. 59, pp. 817-58.

__ (1993), "Exactly Median-Unbiased Estimation of First-Order Autoregressive/Unit Root Models," Econometrica, Vol. 61, pp. 139-65.

Andrews, Donald and Hong-Yuan Chen, (1994), "Approximately Median-Unbiased Estimation of Autoregressive Models," Journal of Business and Economic Statistics, Vol. 12, pp. 187-204.

Bergin, Paul and Robert Feenstra, (1999), "Pricing to Market, Staggered Contracts, and Real Exchange Rate Persistence," NBER Working Paper 7026, (Cambridge: National Bureau of Economic Research).

Cashin, Paul, Hong Liang and C. John McDermott, (2000), "How Persistent are Shocks to World Commodity Prices?," IMF Staff Papers, Vol. 47, pp.177-217.

Cermeno, Rodolfo, (1999), "Median-Unbiased Estimation in Fixed Effects Dynamic Panels," Annales d'Economie et de Statistique, Vol. 55-56, pp. 351-68.

Cheung, Yin-Wong and Kon S. Lai, (2000a), "On Cross-Country Differences in the Persistence of Real Exchange Rates," Journal of International Economics, Vol. 52, pp. 375-97.

- (2000b), "On the Purchasing Power Parity Puzzle," Journal of International Economics, Vol. 52, pp. 321-30.

Corbae, Dean and Sam Ouliaris, (1988), "Cointegration and Tests of Purchasing Power Parity," Review of Economics and Statistics, Vol. 70, pp. 508-11.

DeJong, David, John C. Nankervis, N.E. Savin and Charles H. Whiteman, (1992), "Integration Versus Trend Stationarity in Time Series," Econometrica, Vol. 60, pp. 423-33.

Dickey, David and Wayne Fuller, (1979), "Distribution of the Estimators for Autoregressive Time Series with a Unit Root," Journal of the American Statistical Association, Vol. 74, pp. 427-31.

Dornbusch, Rudiger, (1976), "Expectations and Exchange Rate Dynamics," Journal of Political Economy, Vol. 84, pp. 1161-76. 
Edison, Hali, Joseph Gagnon, and William Melick, (1997), "Understanding the Empirical Literature on Purchasing Power Parity: the Post-Bretton Woods Era," Journal of International Money and Finance, Vol. 16, pp. 1-17.

Engel, Charles, (2000), "Long-Run PPP May Not Hold After All," Journal of International Economics, Vol. 57, pp. 243-73.

Frankel, Jacob, (1986), "International Capital Mobility and Crowding Out in the U.S. Economy: Imperfect Integration of Financial Markets or of Goods Markets?," in R. Hafer (ed.), How Open is the U.S. Economy?, (Lexington: Lexington Books).

— Reversion Within and Between Countries," Journal of International Economics, Vol. 40 , pp. 209-40.

Froot, Kenneth A. and Kenneth Rogoff, (1995), "Perspectives on PPP and Long-Run Real Exchange Rates," in Handbook of International Economics, Vol. 3, edited by Gene Grossman and Kenneth Rogoff, (Amsterdam: Elsevier).

Hall, Alastair R., (1994), "Testing for a Unit Root in Time Series with Pretest Data-Based Model Selection," Journal of Business and Economic Statistics, Vol. 12, pp. 461-70.

Isard, Peter, (1995), Exchange Rate Economics, (Cambridge: Cambridge University Press).

Lothian, James R. and Mark P. Taylor, (1996), "Real Exchange Rate Behavior: The Recent Float from the Perspective of Two Centuries," Journal of Political Economy, Vol.104, pp. 488-509.

Marriott, F.H.C. and J.A. Pope, (1954), "Bias in the Estimation of Autocorrelations," Biometrika, Vol. 41, 390-402.

McDermott, C. John, (1996), "Estimation of the Near Unit Root Model of Real Exchange Rates," Working Paper 96/50, (Washington: International Monetary Fund).

Meese, Richard A. and Kenneth Rogoff, (1983), "Empirical Exchange Rate Models of the Seventies: Do They Fit Out of Sample?," International Economic Review, Vol. 14, pp. 3-24.

Murray, Christian and David Papell (2000), "The Purchasing Power Parity Paradigm," mimeo, Department of Economics, University of Houston.

Ng, Serena and Pierre Perron, (1995), "Unit Root Tests in ARMA models with DataDependent Methods for the Selection of the Truncation Lag," Journal of the American Statistical Association, Vol. 90, pp. 268-81. 
Obstfeld, Maurice and Kenneth Rogoff, (2000), “The Six Major Puzzles in International Macroeconomics: Is There A Common Cause?," NBER Working Paper 7777, (Cambridge: National Bureau of Economic Research).

O'Connell, Paul G.J., (1998), "The Overvaluation of Purchasing Power Parity," Journal of International Economics, Vol. 44, pp. 1-19.

Orcutt, Guy H., (1948), "A Study of the Autoregressive Nature of the Time Series Used for Tinbergen's Model of the Economic System of the United States, 1891-1932," Journal of the Royal Statistical Society, Series B, Vol. 10, pp. 1-48.

—, and Herbert S. Winokur, (1969), "First Order Autoregression: Inference, Estimation and Prediction," Econometrica, Vol. 37, pp. 1-14.

Papell, David H., (1997), "Searching for Stationarity: Purchasing Power Parity Under the Current Float," Journal of International Economics, Vol. 43, pp. 313-32.

Phillips, Peter C.B., (1987), "Time Series Regression with a Unit Root," Econometrica, Vol. 55, pp. 277-301.

—, and Pierre Perron, (1988), "Testing for a Unit Root in Time Series Regression," Biometrika, Vol. 75, pp. 335-46.

Rogoff, Kenneth, (1992), "Traded Goods Consumption Smoothing and the Random Walk Behavior of the Real Exchange Rate," Bank of Japan Monetary and Economic Studies, Vol. 10, pp. 1-29.

- (1996), "The Purchasing Power Parity Puzzle," Journal of Economic Literature, Vol. 34, pp. 647-68.

Rudebusch, Glenn D., (1992), “Trends and Random Walks in Macroeconomic Time Series: A Re-examination," International Economic Review, Vol. 33, pp. 661-80.

Shaman, Paul and Robert A. Stine, (1988), "The Bias of Autoregressive Coefficient Estimators," Journal of the American Statistical Association, Vol. 83, pp. 842-48.

Stock, James H., (1991), "Confidence Intervals for the Largest Autoregressive Roots in U.S. Macroeconomic Time Series," Journal of Monetary Economics, Vol. 28, pp. $435-59$.

Taylor, Mark P. and Lucio Sarno, (1998), "The Behavior of Real Exchange Rates in the PostBretton Woods Period," Journal of International Economics, Vol. 46, pp. 281-312.

- (2000), "Potential Pitfalls for the Purchasing-Power Parity Puzzle? Sampling and Specification Biases in Mean-Reversion Tests of the Law of One Price," Econometrica, forthcoming. 
White, Halbert, (1980), "A Heteroskedasticity-Consistent Covariance Estimator and a Direct Test for Heteroskedasticity," Econometrica, Vol. 48, pp. 817-38.

Wickham, Peter, (1993), "A Cautionary Note on the Use of Exchange Rate Indicators," PPAA/93/5, (Washington: International Monetary Fund).

Wu, Yangru, (1996), "Are Real Exchange Rates Nonstationary? Evidence from a Panel-data Test," Journal of Money, Credit and Banking, Vol. 28, pp. 54-63.

Zanello, Alessandro and Dominique Desruelle, (1997), "A Primer on the IMF's Information Notice System," Working Paper 97/71, (Washington: International Monetary Fund). 